\title{
Actualidad de la Jurisprudencia de la Corte Interamericana de Derechos Humanos, de la Corte Suprema de Justicia de la Nación, de la Suprema Corte de Justicia de la Provincia de Buenos Aires y Tribunales inferiores
}

\begin{tabular}{l|l} 
Fernando Amosa & $\mid \begin{array}{l}\text { Universidad Católica de La Plata, } \\
\text { Argentina }\end{array}$
\end{tabular}

Juan Francisco Díaz ${ }^{2}$ Universidad Nacional de La Plata, James Vértiz Medina ${ }^{3}$ Argentina

Revista Derechos en Acción ISSN 2525-1678/ e-ISSN 2525-1686

Año 4/No 13, Primavera 2019 (21 septiembre a 20 diciembre), 451-484

DOI: https://doi.org/10.24215/25251678e346

ORCID: https://orcid.org/0000-0002-2706-1650

https://orcid.org/0000-0002-5891-7845

https://orcid.org/0000-0003-2261-1999

\section{Corte IDH. Caso Girón y otro Vs. Guatemala. Excepción Pre- liminar, Fondo, Reparaciones y Costas. Sentencia de 15 de octubre de 2019. Serie C No. 390}

I. Hechos: Los hechos del caso versan sobre la alegada responsabilidad del Estado por varias violaciones a garantías mínimas cometidas en el marco del proceso penal contra

\footnotetext{
1 Abogado (UCALP), docente del Instituto Provincial de la Administración Pública (IPAP) y asistente jurídico del Ministerio de Jefatura de Gabinete de Ministros de la Provincia de Buenos Aires. Email: Fernando.amosa@gmail.com

2 Abogado (UNLP), docente de la Facultad de Ciencias Jurídicas y Sociales de la UNLP. Email: juanfranciscodiaz87@gmail.com

3 Abogado (UNLP), docente del Instituto de Derechos Humanos de la Facultad de Ciencias Jurídicas y Sociales de la UNLP. Email: jamesvertiz@hotmail.com
} 
Roberto Girón y Pedro Castillo Mendoza por los delitos de violación calificada y asesinato, que culminó con la imposición de la pena de muerte, y sus ejecuciones televisadas por medio de un pelotón de fusilamiento.

II. Fondo: El Tribunal de San José, se ocupó en el caso de considerar y resolver el fondo de la controversia sobre la imposición obligatoria de la pena de muerte de los señores Roberto Girón y Pedro Castillo Mendoza, la alegada violación a la integridad personal por la permanencia de los mismos en el denominado "corredor de la muerte", y la presunta vulneración a las garantías judiciales.

A efectos de examinar la alegada violación del derecho a la vida de los señores Roberto Girón y Pedro Castillo, preliminarmente la Corte recordó su reciente postura sentada en el caso Martínez Coronado Vs. Guatemala (2019). Allí subrayó que, en los casos excepcionales en los cuáles está permitida a los Estados la aplicación de la pena de muerte, tal posibilidad está sujeta a un conjunto de rigurosas limitaciones. Que, tal como lo dispone la Convención Americana, la pena de muerte no podrá imponerse sino para los delitos más graves (artículo 4.2) y por la otra, se excluye de modo absoluto su aplicación por delitos políticos o por delitos comunes conexos con los políticos (artículo 4.4). Que la circunstancia de que dicho instrumento reduzca el ámbito posible de aplicación de la pena de muerte a los delitos comunes más graves y no conexos, es reveladora del propósito de considerar dicha pena aplicable sólo en condiciones excepcionales.

También advirtió que los Estados tienen el deber de proteger a todas las personas al evitar delitos, sancionar a los responsables y mantener el orden público, particularmente cuando se trata de hechos como los que dieron origen al proceso penal seguido contra de los señores Girón y Castillo Mendoza, en el sentido de que la lucha de los Estados contra el crimen debe desarrollarse dentro de los límites y conforme a los procedimientos que permitan preservar tanto la seguridad pública como el pleno respeto a los derechos humanos. 
Sobre la imposición obligatoria de la pena de muerte, la Corte nota que en la sentencia del Juzgado de Primera Instancia, el juzgador impuso dicha sanción, pena de muerte, de manera obligatoria, como lo establecía el artículo 175 del Código Penal, sin tomar en consideración las circunstancias atenuantes o agravantes. El Tribunal recordó lo señalado en el caso Raxcacó Reyes Vs. Guatemala (2005), remitiéndose al Comité de Derechos Humanos de Naciones Unidas, que consideró "que la obligatoriedad de la pena capital con la que se priva al sujeto de su derecho a la vida, impide considerar si, en las circunstancias particulares del caso, esta forma excepcional de castigo es compatible con las disposiciones del Pacto Internacional de Derechos Civiles y Políticos", así como lo señalado por este Tribunal en el caso Hilaire, Constantine y Benjamín y otros Vs. Trinidad y Tobago (2002) respecto de cómo se trataba a los acusados en aplicación de la pena de muerte obligatoria.

Que el artículo 175 del Código Penal de Guatemala, tal como estaba redactado, no contemplaba la aplicación de una pena distinta a la pena de muerte, por la comisión del delito de violación calificada, en los casos en que la víctima no hubiera cumplido los diez años de edad. La norma indicada no permitía valorar las características específicas del delito, ni el grado de participación y de culpabilidad del acusado, circunstancias que podrían atenuar la sanción impuesta. La regulación de dicho delito ordenaba de manera automática la aplicación de la pena de muerte a sus autores.

Por lo que la condena a pena de muerte de los señores Roberto Girón y Pedro Castillo Mendoza se fundó en la aplicación de la pena impuesta en el artículo 175 del Código Penal, vigente al momento de la sentencia, la Corte consideró que el Estado violó la prohibición de la privación arbitraria de la vida establecida en el artículo 4.1 y 4.2 de la Convención Americana, en relación con los artículos 1.1 y 2 de la Convención, en perjuicio de los señores Girón y Castillo.

Respectó el derecho a la integridad personal, la Corte enfatizó que tuvo ya la oportunidad de pronunciarse al respecto 
del llamado "fenómeno del corredor de la muerte" en el caso Hilaire, Constantine y Benjamin y otros vs. Trinidad y Tobago y en el caso Raxcacó Reyes vs. Guatemala, en los que luego de realizar una valoración de los peritajes aportados relativos a las condiciones de detención específicas y propias de las personas condenadas a muerte y víctimas del caso, así como sobre el impacto concreto sobre ellas, condujeron a una violación de los artículos 5.1 y 5.2 de la Convención Americana.

Asimismo dijo, el Tribunal Europeo de Derechos Humanos, el Sistema Universal de Derechos Humanos y algunos tribunales nacionales advierten que el llamado "corredor de la muerte" causa una afectación al derecho a la integridad personal por la angustia en la que se encuentran las personas condenadas a muerte, situación, que genera traumas psicológicos por la manifestación presente y creciente de la ejecución de la pena máxima, por ende, es considerado como un trato cruel inhumano y degradante. Por lo tanto para determinar la existencia de una violación a la integridad personal derivada del "corredor de la muerte", es necesario analizar las circunstancias personales y particulares del caso para poder valorar si la permanencia en el mismo alcanzó el nivel de gravedad para calificarse como cruel, inhumano o degradante.

Por otro lado, respecto al medio utilizado para la ejecución de la pena de muerte, la Corte notó que diversos órganos especializados, así como, criterios del sistema universal y otros sistemas regionales de protección de derechos humanos prohíben expresamente los modos de ejecución de la pena capital que causen mayor dolor y sufrimiento. En este sentido, es importante advertir, que todos los medios de ejecución pueden infligir "dolor" o "sufrimientos intensos", por tal motivo, si un Estado ejecuta la pena de muerte debe hacerlo de la forma que cause menor sufrimiento posible, ya que cualquiera que sea el método de ejecución, la extinción de la vida implica algún dolor físico.

Puso de resalto que, diversos órganos internacionales han indicado que métodos de ejecución como la lapidación, la asfixia con gas, "la inyección de sustancias letales no ensayadas, 
[...] la incineración y el enterramiento con vida[,] las ejecuciones públicas [, así como] [...] otros modos de ejecución dolorosos o humillantes", constituyen tratos crueles inhumanos y degradantes que vulneran el derecho a la integridad personal.

También destacó, tal como lo hace el Relator Especial sobre ejecuciones extrajudiciales de naciones Unidas, que las ejecuciones públicas constituyen un incumplimiento de la prohibición de los tratos o penas crueles, inhumanas o degradantes.

Asimismo, el Tribunal Interamericano advirtió que la publicidad de la ejecución de los señores Girón y Castillo a través de los medios televisivos es incompatible con la dignidad humana, por constituirse como un trato degradante, toda vez, que las presuntas víctimas del presente caso fueron tratados como objetos para ejemplificar, a través de su ejecución, que determinadas conductas eran rechazadas por la sociedad en Guatemala.

Por tales motivo, la Corte concluyó que los señores Girón y Castillo enfrentaron graves sufrimientos psíquicos provenientes de la angustia de saberse en el "corredor de la muerte" tras un procedimiento que tuvo numerosas falencias, así como por la publicidad de la ejecución, lo cual fue violatorio de su derecho a la integridad física, psíquica y moral, contenido en el artículo 5.1 de la Convención Americana y han constituido un trato cruel, inhumano y degradante contrario al artículo 5.2 de la misma.

En relación al derecho a las garantías judiciales, la Corte señaló que el derecho a la defensa se proyecta en dos facetas dentro del proceso penal: por un lado, a través de los propios actos del inculpado, siendo su exponente central la posibilidad de rendir una declaración libre sobre los hechos que se le atribuyen y, por el otro, por medio de la defensa técnica, ejercida por un profesional del derecho, quien cumple la función de asesorar al investigado sobre sus deberes y derechos y ejecuta, inter alia, un control crítico y de legalidad en la producción de pruebas.

La Corte a continuación pasó a delinear una serie de estándares sobre el derecho a la defensa que merecen ser abordados. 
Indicó que el derecho de defensa implica que esta sea eficaz, oportuna, realizada por personal técnico, que permita fortalecer la protección del interés concreto del imputado y no como un simple medio para cumplir formalmente con la legitimidad del proceso. Por ende, cualquier forma de defensa aparente resultaría violatoria de la Convención Americana.

Que la defensa pública corresponde a una función estatal o servicio público, pero se considera una función que debe gozar de la autonomía necesaria para ejercer adecuadamente sus funciones de asesorar según su mejor juicio profesional y en atención a los intereses del imputado, estimando la Corte que el Estado no puede ser considerado responsable de todas las fallas de la defensa pública, dado la independencia de la profesión y el juicio profesional del abogado defensor. En este sentido, como parte del deber estatal de garantizar una adecuada defensa pública, es necesario implementar adecuados procesos de selección de los defensores públicos, desarrollar controles sobre su labor y brindarles capacitaciones periódicas.

Que nombrar a un defensor de oficio con el sólo objeto de cumplir con una formalidad procesal equivaldría a no contar con defensa técnica, por lo que es imperante que dicho defensor actúe de manera diligente con el fin de proteger las garantías procesales del acusado y evite así que sus derechos se vean lesionados y se quebrante la relación de confianza. A tal fin, es necesaria que la institución de la defensa pública, como medio a través del cual el Estado garantiza el derecho irrenunciable de todo inculpado de delito de ser asistido por un defensor, sea dotada de garantías suficientes para su actuación eficiente y en igualdad de armas con el poder persecutorio. Que para cumplir con este cometido el Estado debe adoptar todas las medidas adecuadas, entre ellas, contar con defensores idóneos y capacitados que puedan actuar con autonomía funcional.

Que la asistencia jurídica debe ser ejercida por un profesional del derecho para poder satisfacer los requisitos de una defensa técnica a través de la cual se asesore a la persona sometida a proceso, inter alia, sobre la posibilidad de ejercer 
recursos contra actos que afecten derechos. Es por ello, que la Corte confirmó, que en los casos de los procesos penales, la defensa tiene que ser ejercida por un profesional del derecho dado que significa una garantía del debido proceso y que el investigado será asesorado sobre sus deberes y derechos y de que ello será respetado. Un abogado, asimismo, puede realizar, inter alia, un control crítico y de legalidad en la producción de pruebas y puede compensar adecuadamente la situación de vulnerabilidad de las personas privadas de libertad en relación con el acceso efectivo a la justicia en términos igualitarios.

En el caso, los señores Roberto Girón y Pedro Castillo fueron acusados el 18 de abril de 1993 por el delito de violación calificada, cuyo proceso penal culminó con una sentencia condenatoria a pena de muerte. En el presente, la discusión jurídica se centra en analizar si en el proceso penal tramitado a las presuntas víctimas se les respetó el derecho de defensa, en particular, si el Estado les proporcionó una defensa técnica adecuada, ya que según lo alegado por la Comisión y las representantes, no contaron con una defensa letrada en por los menos tres diligencias y, posteriormente, los defensores nombrados de oficio fueron estudiantes de derecho, lo cual tuvo una incidencia negativa en el resultado del proceso en su perjuicio.

En el caso bajo análisis, la Corte concluyó que los señores Roberto Girón y Pedro Castillo no contaron con la asistencia de un defensor al inicio del proceso, etapa en la cual se realizaron diligencias de importancia esencial como fueron la rendición de sus declaraciones indagatorias, el decreto de la prisión preventiva y el careo efectuado por el juez de instrucción, pese a que para esta última diligencia, ya habían sido nombrados los correspondientes defensores, el 27 de abril de 1993, todo lo cual ocasionó la violación del artículo 8.2.d) de la Convención. Además, no es un hecho controvertido, que la defensa pública de oficio designó a dos estudiantes de derecho para ejercer la defensa de las presuntas víctimas.

III. Reparaciones: La Corte indicó que toda violación de una obligación internacional que haya producido daño comporta el 
deber de repararlo adecuadamente, y que esa disposición recoge una norma consuetudinaria que constituye uno de los principios fundamentales del Derecho Internacional contemporáneo sobre responsabilidad de un Estado.

Respecto de la solicitud de medidas de no repetición, la Corte estimo no hacer lugar a las mismas, toda vez que el Estado ya había efectuado las modificaciones referentes a la peligrosidad del agente respecto del artículo 132 del Código Penal de Guatemala y la derogación del artículo 175 del Código Penal.

\section{Corte IDH. Caso Perrone y Preckel Vs. Argentina. Excepcio- nes Preliminares, Fondo, Reparaciones y Costas. Sentencia de 8 de octubre de 2019. Serie C No. 384 .}

I. Hechos: El caso se relaciona con la violación de los derechos a las garantías judiciales y protección judicial en los procesos administrativos y judiciales iniciados por Elba Clotilde Perrone y Juan José Preckel a efectos de solicitar el pago de los salarios y beneficios sociales dejados de percibir en la entidad estatal en la que laboraban, como consecuencia de su alegada privación arbitraria de libertad por parte de agentes estatales durante la dictadura militar.

II. Fondo: El Tribunal Interamericano evaluó si el Estado argentino garantizó el acceso a un recurso adecuado y efectivo y con las debidas garantías procesales, particularmente a través del deber de motivación y el plazo razonable, a la luz del alcance de los derechos reconocidos en los artículos 8 y 25 de la Convención Americana.

Respecto del deber de motivar y el derecho a la protección judicial en los procesos iniciados por la Sra. Perrone y el Sr. Preckel para obtener una indemnización de carácter individual complementaria a la reparación administrativa recibida a través de la Ley 24.043, la Corte recordó su estándar jurisprudencial sentado al respecto en el caso García Lucero vs. Chile (2013) en donde sostuvo el carácter concurrente que puede existir entre medidas colectivas de reparación administrativa y el acceso a recursos en reclamo de reparaciones individuales. 
Asimismo, reiteró lo sentado en el caso Órdenes Guerra Vs. Chile (2018), considerando que "[...] el criterio jurisprudencial prevaleciente actualmente a nivel interno, acerca del carácter complementario y no excluyente de reparaciones otorgadas en vías administrativa y judicial es razonable en relación con el derecho de víctimas de graves violaciones de derechos humanos de acceder a la justicia para solicitar una declaratoria judicial de responsabilidad estatal, ya sea que se efectúe una determinación individual de daños o, en su caso, para cuestionar la suficiencia o efectividad de reparaciones recibidas con anterioridad".

También destacó el Tribunal de San José que de existir mecanismos nacionales para determinar formas de reparación, esos procedimientos y sus resultados deben ser valorados, ya que constituyen un esfuerzo por parte del Estado en dirección de un proceso colectivo de reparación y de paz social.

En el presente caso, la Corte constató que las presuntas víctimas iniciaron sus recursos administrativos y judiciales años antes de la emisión de la Ley 24.043, que entró en vigor el 2 de enero de 1992. Particularmente, a través de los recursos administrativos de fechas 1983 y 1985 y judiciales en 1988. Posteriormente, la señora Perrone y el señor Preckel recibieron indemnizaciones derivadas de la Ley 24.043 en los años 1995 y 1994, respectivamente. En particular, la Corte notó que en los hechos concretos de este caso, el beneficio específico que recibieron los peticionarios a través de la Ley 24.043, no fue un excluyente por parte de las autoridades para continuar con las vías judiciales que habían emprendido y se encontraban en proceso.

La Corte sostuvo que el deber de motivación es una de las debidas garantías incluidas en el artículo 8.1 para salvaguardar el derecho a un debido proceso. Es una garantía vinculada con la correcta administración de justicia que protege el derecho a ser juzgado por las razones que el derecho suministra, y otorga credibilidad de las decisiones jurídicas en el marco de una sociedad democrática. Las decisiones que adopten los órganos internos que puedan afectar derechos humanos deben 
estar debidamente fundamentadas, pues de lo contrario serían decisiones arbitrarias. En este sentido, la argumentación de un fallo y de ciertos actos administrativos deben permitir conocer cuáles fueron los hechos, motivos y normas en que se basó la autoridad para tomar su decisión, a fin de descartar cualquier indicio de arbitrariedad.

En concordancia con lo anterior, la Corte reitera en el caso que los Estados tienen el deber de garantizar, a todas las personas bajo su jurisdicción, un recurso judicial efectivo contra actos violatorios de sus derechos fundamentales. Esto implica que el recurso judicial debe ser idóneo para combatir la violación, por lo que la autoridad competente debe examinar las razones invocadas por el demandante y pronunciarse en torno a ellas. En ese sentido, el Tribunal subrayó que el análisis por la autoridad competente de un recurso judicial, no puede reducirse a una mera formalidad y omitir argumentos de las partes, ya que debe examinar sus razones y manifestarse sobre ellas conforme a los parámetros establecidos por la Convención Americana.

En lo que se refiere específicamente a la efectividad del recurso, esta Corte ha establecido que el sentido de la protección del artículo es la posibilidad real de acceder a un recurso judicial para que una autoridad competente y capaz de emitir una decisión vinculante, determine si ha habido o no una violación a algún derecho que la persona que reclama estima tener y que, en caso de ser encontrada una violación, el recurso sea útil para restituir al interesado en el goce de su derecho y repararlo. Lo anterior no implica que se evalúe la efectividad de un recurso en función de que éste produzca un resultado favorable para el demandante.

La Corte observó que tanto en el caso del señor Preckel como en el caso de la señora Perrone las decisiones judiciales que quedaron en firme desestimaron las solicitudes presentadas por las presuntas víctimas con base en la aplicación de la normativa interna que señalaba que no había lugar a percibir salarios por servicios no prestados. No obstante, a lo largo de los procesos judiciales el señor Preckel y la señora Perrone 
argumentaron de forma reiterada que la normativa interna autorizaba el pago de salarios y haberes laborales no percibidos en casos de fuerza mayor, y alegaron que su detención arbitraria (y el posterior exilio en el caso del señor Preckel) sería una causal de fuerza mayor y que por lo tanto estaba justificado el pago de los haberes dejados de percibir pese a que no habían laborado.

Sin entrar a determinar cuál era la tesis correcta a la luz del derecho interno, la Corte advirtió que las decisiones judiciales que decidieron de forma definitiva las demandas presentadas por el señor Preckel y la señora Perrone motivaron de forma suficiente por qué no eran aplicable las excepciones que alegaban al principio establecido normativa y jurisprudencialmente de que no procede el pago de sueldo por funciones no prestadas. Además de explicar que en estos casos se debatía la responsabilidad de la DGI como empleador y no la responsabilidad del Estado por los actos ilegítimos del gobierno de facto de los cuales habían sido víctimas los demandantes.

Consecuentemente, el Tribunal concluyó que el Estado argentino no es responsable por la violación a los artículos 8.1 y 25 de la Convención Americana, en relación con las obligaciones previstas en el artículo 1.1 del mismo instrumento, respecto de la señora Elba Clotilde Perrone y el señor Juan José Preckel.

Ahora, sobre la garantía del plazo razonable, la Corte señaló que la razonabilidad del plazo debe apreciarse en relación con la duración total del proceso, desde el primer acto procesal hasta que se dicte sentencia definitiva, incluyendo los recursos de instancia que pudieran eventualmente presentarse. De acuerdo con el artículo 8.1 de la Convención y como parte del derecho a la justicia, los procesos deben realizarse dentro de un plazo razonable, por lo que, en atención a la necesidad de garantizar los derechos de las personas perjudicadas, una demora prolongada puede llegar a constituir, por sí misma, una violación de las garantías judiciales.

En tal sentido recordó que los cuatro elementos para determinar la razonabilidad del plazo: i) la complejidad del asunto; ii) la actividad procesal del interesado; iii) la conducta de las 
autoridades judiciales, y iv) la afectación generada por la situación jurídica de la persona involucrada en el proceso.

En el presente caso para estudiar la alegada violación de la garantía del plazo razonable, la Corte estimó pertinente examinar la duración del procedimiento administrativo y del proceso judicial de forma conjunta, pues el trámite de la reclamación administrativa era un presupuesto necesario para acudir a la vía jurisdiccional como manifestaron las víctimas al presentar las demandas correspondientes antes el juez federal. En vista de lo anterior los procedimientos administrativo y judicial duraron trece años y catorce días en el caso de la señora Perrone (de los cuales más de once años transcurrieron a partir de la ratificación de la Convención Americana y el reconocimiento por parte de Argentina de la competencia contenciosa de la Corte) y aproximadamente diez años y once meses en el caso del señor Preckel.

Al respecto la Corte concluyó que la duración de diez años y once meses en el caso del señor Preckel y de más de once años, a partir del reconocimiento de la competencia contenciosa de la Corte, en el caso de la señora Perrone del procedimiento administrativo y del proceso judicial en su conjunto, excedió el plazo razonable de manera injustificada, en contravención del artículo 8.1 de la Convención Americana.

III. Reparaciones: El Tribunal indicó que toda violación de una obligación internacional que haya producido daño comporta el deber de repararlo adecuadamente, y que esa disposición recoge una norma consuetudinaria que constituye uno de los principios fundamentales del Derecho Internacional contemporáneo sobre responsabilidad de un Estado.

La Corte ordenó que en el plazo de seis meses contado a partir de la notificación de la presente Sentencia, realice las siguientes publicaciones: a) el resumen oficial de la Sentencia elaborado por la Corte, por una sola vez, en el Diario Oficial, en un diario de amplia circulación nacional en un tamaño de letra legible y adecuado, y b) la presente Sentencia en su integridad, 
disponible al menos por un período de un año, en el sitio web del Centro de Información Judicial, de manera accesible al público.

En relación al pretendido pago de una suma equivalente a los salarios caídos y los haberes dejados de percibir durante el período de su detención ilegal en el caso de la señora Perrone, y de la detención ilegal y el exilio forzoso en caso del señor Preckel, atento a que se vincula con hechos sobre los que el Tribunal no se pronunció, por estar fuera de su competencia temporal, consideró improcedente ordenar esta medida compensatoria.

\section{Novedades de la Corte Suprema de Justicia de la Nación}

\section{La Corte Suprema de la Nación volvió a denegar el beneficio del $2 \times 1$ a represores}

Con los votos de los Dres. Juan Carlos Maqueda, Horacio Rosatti, Ricardo Lorenzetti y Elena Highton de Nolasco, la Corte Suprema de la Nación volvió a denegar a represores el pedido del beneficio conocido como " $2 x 1$ " establecido por la ley 24.390, por el cual a partir de los dos años de prisión preventiva, los días de prisión se computarían doble.

En minoría, el Presidente de la Corte, Carlos Rosenkrantz, mantuvo la misma postura que pregonó desde su ingreso al máximo tribunal, por la cual cree que el beneficio del 2x1 es enteramente aplicable a delitos de lesa humanidad y que la ley interpretativa sancionada con posterioridad es de carácter inconstitucional (CSJN "Hidalgo Garzón", "Azic", "Morel", "Weber", "Ruffo" y "Gallone", 25 de septiembre de 2019).

\section{La Corte Suprema definió que la reducción del IVA y del im- puesto a las ganancias lo deberá afrontar el Estado Nacional}

Con el voto de los Dres. Juan Carlos Maqueda, Ricardo Lorenzetti y Horacio Rosatti (y la disidencia de Carlos Rosenkrantz), la Corte Suprema hizo lugar a una medida cautelar interpuesta por la provincia de Entre Ríos que solicitaba suspender los decretos sancionados por el Gobierno que reducían el IVA al cero por ciento para ciertos alimentos de la canasta básica y el pago de impuesto 
a las ganancias para determinados sujetos, ya que dichas medidas afectaban fondos coparticipables de las provincias.

En ese sentido, tuvieron en cuenta que las leyes-convenio y los denominados "pactos fiscales", hacen las bases de un federalismo de concertación con un régimen federal de coparticipación de impuestos basado en la reforma constitucional de 1994 y que dichas leyes-convenio son herramientas de coordinación no susceptibles de ser modificadas unilateralmente. (CSJN "Entre Ríos, Provincia de c/ Estado Nacional s/ acción declarativa de inconstitucionalidad incidente de medida cautelar", 1 de octubre de 2019).

\section{La Corte Suprema revocó un fallo que se apartó de las pau- tas exigidas para los procesos colectivos}

Es en el marco de un amparo iniciado por el Matadero Municipal de la localidad rionegrina de Luis Beltrán que cuestionaba el aumento de tarifas de gas dispuesto por el Ministerio de Energía y Minería de la Nación en abril de 2016, la Corte Suprema de Justicia de la Nación revocó una sentencia de la Cámara Federal de General Roca que había reconocido el carácter colectivo a un amparo interpuesto por el Matadero Municipal de Luis Beltrán.

La acción se originó a partir de que el titular del Matadero Municipal de la ciudad rionegrina había promovido una acción de amparo contra el Ministerio de Energía y Minería de la Nación, el ENARGAS, y Camuzzi Gas del Sur S.A.,cuestionando las Resoluciones 28/2016 y 31/2016 del Ministerio de Energía y Minería de la Nación que determinaban un aumento del régimen tarifario para el servicio público de gas natural a partir del $1^{\circ}$ de abril de 2016 (CSJN "Matadero Municipal de Luis Beltrán S.E. c/ Estado Nacional-Ministerio de Energía y Minería de la Nación-y otros s/ amparo ley 16.986", 17 de octubre de 2019).

La Corte Suprema rechazó actualizar remuneraciones de jueces por inflación

La Corte Suprema de Justicia de la Nación integrada por cinco conjueces por primera vez desde la llegada de Horacio 
Rosatti y Carlos Fernando Rosenkrantz al máximo tribunal, resolvió rechazar más de 50 demandas interpuestas por jueces y un Fiscal General de la Nación que reclamaban una actualización de salarios según el índice de precios al consumidor, a partir de octubre de 1991 y por los siguientes cinco o más años.

En su presentación, los funcionarios judiciales pretendían una recomposición salarial similar a la que la Corte Suprema había otorgado mediante la acordada 56/91, originada a partir de la hiperinflación producida en el año 1988, fundada en la intangibilidad de las remuneraciones de los magistrados según el artículo 110 de la Constitución Nacional y el fallo "Bonorino Peró" de la Corte Suprema (CSJN "Álvarez, Gladys Stella y otros c/ EN CSJN - Consejo de la Magistratura - art. $110 \mathrm{~s} /$ empleo público", 5 de noviembre de 2019).

\section{La Corte Suprema rechazó el pedido de prisión domiciliaria de Miguel Etchecolatz}

Con los votos de los jueces Juan Carlos Maqueda, Elena Highton de Nolasco, Ricardo Lorenzett y Horacio Rosatti, la Corte Suprema de Justicia de la Nación desestimó la queja presentada por la defensa de Miguel Osvaldo Etchecolatz al considerar inadmisible su recurso extraordinario interpuesto ante la decisión de la Sala IV de la Cámara Federal de Casación Penal.

Previamente, el Tribunal Oral en lo Criminal Federal $N^{\circ} 6$ había dispuesto en diciembre de 2018 la prisión domiciliaria de Etchecolatz por problemas de salud. Ante esa resolución, el doctor Pablo Llonto, en representación de la parte querellante y la doctora María Ángeles Ramos, representante del Ministerio Público Fiscal, interpusieron recurso de casación (CSJN "Recurso de hecho deducido por la defensa en la causa Etchecolatz, Miguel Osvaldo s/ incidente de recurso extraordinario", para decidir sobre su procedencia", 12 de noviembre de 2019). 


\section{La Corte Suprema revocó un fallo sobre indemnización por incapacidad laboral por apartarse de la ley}

Con los votos de los jueces Carlos Rosenkrantz y Juan Carlos Maqueda y la jueza Elena Highton de Nolasco, la Corte Suprema de Justicia de la Nación revocó una sentencia de Sala VII de la Cámara Nacional de Apelaciones del Trabajo, por no tener en consideración la aplicación obligatoria del baremo de grados de incapacidad para el trabajador.

El máximo tribunal resolvió que según las leyes de Riesgos de Trabajo ( $\mathrm{N}^{\circ}$ 24.557) y del Régimen de reparación de daños derivados de accidentes laborales y enfermedades ( $\left.\mathrm{N}^{\circ} 26.773\right)$, los organismos administrativos como los jurisdiccionales "tienen el deber de ajustar sus informes, dictámenes y pronunciamientos a la Tabla de Evaluación de Incapacidades prevista como Anexo del Decreto 659/96". En consecuencia, correspondió la descalificación del fallo apelado en este aspecto con arreglo a la doctrina de la Corte en materia de sentencias arbitrarias (CSJN "Recurso de becho deducido por Asociart ART S.A. en la causa Ledesma, Diego Marcelo c/ Asociart ART S.A. s/ accidente - ley especial”, 12 de noviembre de 2019).

\section{La Corte determinó la competencia federal sobre un caso que involucra al antiguo Zoológico de Buenos Aires}

La Corte Suprema de Justicia de la Nación resolvió otorgar la competencia al Juzgado Nacional en lo Criminal y Correccional Federal $\mathrm{N}^{\circ} 11$, sobre un caso de posible comisión del delito de tráfico ilegal de animales. La contienda se originó a partir de la denuncia del Coordinador Nacional de la Federación Argentina Veterinaria, quien manifestó que las condiciones ambientales en las cuales vivían los elefantes del zoológico de la Ciudad Autónoma de Buenos Aires les provocaban problemas de salud y en algunos casos la muerte. Asimismo, de la investigación llevada a cabo por el Fiscal a cargo de la Unidad Especializada en Medio Ambiente, se dilucidó el posible delito de tráfico ilegal de animales, penado por la Ley $\mathrm{N}^{\mathrm{o}} 22.421$. 
La Corte Suprema resolvió que ante los escasos elementos de convicción del caso, resulta impediente dilucidar el alcance delictivo de los hechos, a fin de determinar el lugar de comisión de los mismos. En consecuencia, corresponde a la justicia federal, que previno, proseguir el trámite de la causa. En disidencia, el juez Carlos Rosenkrantz y la jueza Elena Highton de Nolasco, consideraron que la contienda de competencia se había trabado entre dos jueces nacionales, por ende, correspondía a la Cámara Nacional de Apelaciones en lo Criminal y Correccional Federal, como tribunal de alzada, dirimir la cuestión conforme al artículo 24, inciso séptimo del Decreto-Ley $\mathrm{N}^{\circ} 1285$ (CSJN "Jardín Zoológico de la Ciudad Autónoma de Buenos Aires s/ incidente de incompetencia. Denunciante: Asociación de Funcionarios y Abogados por los Derechos de los Animales y otros”, 21 de noviembre de 2019).

\section{Novedades de la Suprema Corte de Justicia de la Provincia de Buenos Aires}

\section{La Suprema Corte de Buenos Aires consideró al estrés como Enfermedad Profesional}

La Suprema Corte de Justicia de provincia de Buenos Aires consideró como enfermedad profesional al estrés luego de revocar la sentencia de un Tribunal de Trabajo de la localidad de Junín, el cual había desestimado una acción promovida contra Galeno ART S.A fundado en la ley de riesgos del trabajo y perseguía la indemnización por el fallecimiento del trabajador.

Se destaca del voto del ministro Negri, al cual adhirieron la totalidad de los restantes ministros, que se inmiscuyó en la valoración probatoria -algo poco común en esta instancia- y concluyó que el Tribunal debería haber valorado la pericia medica junto con las posiciones absueltas en rebeldía. De esta manera concluir que las distancias recorridas, junto con la fatiga acumulada, más las patologías padecidas precedentemente, invariablemente conllevan a provocar una enfermedad profesional y concluyente la responsabilidad por parte de la 
aseguradora (SCBA "P., A. F. contra Galeno ART S.A. Enfermedad profesional", 14 de agosto de 2019).

\section{La Suprema Corte bonaerense anuló una Resolución de Conte Grand que ampliaba facultades de los fiscales}

La Suprema Corte de Justicia de la provincia de Buenos Aires resolvió este miércoles anular parcialmente una Resolución dictada por el Procurador General Julio Conte Grand, que ampliaba facultades de los Fiscales Generales en materias que la ley 14.442 no otorgaba, como en cuestiones de medio ambiente, consumidores, procesos contenciosos-administrativos y excusaciones o recusaciones de jueces, entre otros temas.

El acuerdo firmado por la Suprema Corte, que lleva el número 3957, manifiesta que las facultades que el Procurador les concedía a los fiscales carecían de preceptos legales que lo habilitaran expresamente y que ello constituía un exceso en sus competencias. En abril del año pasado, Conte Grand había emitido la Resolución 315/2018 que ampliaba las facultades otorgadas a los fiscales en materia civil, comercial, laboral y de justicia de paz y que se encuentran reguladas por el artículo 29 inciso $4^{\circ}$ de la Ley del Ministerio Público (SCBA Acuerdo 3957/2019, 27 de noviembre de 2019).

\section{La Suprema Corte ratificó la autonomía económica y finan- ciera de los municipios}

La Suprema Corte de la provincia de Buenos Aires, hizo lugar parcialmente a la medida cautelar solicitada por las municipalidades de San Martin y San Fernando, suspendiendo los efectos del artículo 104 de la Ley $\mathrm{N}^{\circ}$ 15.078. Dicha norma, establece que el costo adicional -el excedente que por dicho concepto pagó en el Ejercicio 2018- de la tarifa de energía eléctrica, correspondiente a los asentamientos urbanos y usuarios definidos en el Nuevo Acuerdo Marco celebrado entre el Estado Nacional, la provincia de Buenos Aires, EDENOR S.A., EDESUR S.A. y EDELAP S.A, sea asumido por los respectivos municipios. 
En su resolución, los jueces Eduardo De Lázzari, Daniel Fernando Soria, Luis Esteban Genoud y la jueza Hilda Kogan rechazaron la intervención del Defensor del Pueblo, ya que su "aptitud para representar los intereses invocados no puede ser genérica e ilimitada" y en su presentación "plantea agravios meramente hipotéticos o conjeturales que no habilitan la participación procesal" del mismo.

También, resolvieron que se encontraban configurados los elementos para la petición cautelar, en la medida que la norma invocada "impone a las municipalidades actoras, en modo sorpresivo, una erogación de magnitud ajena al presupuesto previsto para ese mismo ejercicio, su efectiva aplicación podría afectar el normal desenvolvimiento de la autonomía económica financiera" (SCBA "Intendente De La Municipalidad De General San Martin C/ Provincia De Bs. As. S/ Inconst. Decr. 1289/19 Y Art. 104 Ley 15.078”, 27 de noviembre de 2019).

\section{Jurisprudencia Bonaerense}

\section{TRIBUNALES INFERIORES}

Tribunal: Cámara de apelaciones en lo civil y comercial. Azul, Buenos Aires Sala 02

Fallo: Pastor Nancy Susana c/ Di Marco María Cecilia s/ daños y perjuicios

Voces: Propiedad intelectual (Ley $\mathrm{N}^{\circ}$ 11.723), excepción de prescripción, prueba electrónica.

\section{Sumarios:}

- Corresponde confirmar la sentencia que ordena a una mujer indemnizar a una colega por plagiar parte de su tesis doctoral en dos trabajos académicos presentados, omitiendo efectuar las citas y las referencias correspondientes.

- Considera suficiente e indiscutiblemente acreditada la configuración del hecho ilícito civil, consistente en la apropiación y utilización indebida por parte de la demandada, en dos 
obras suyas publicadas, pues realizó la copia de párrafos, ya mediante su transcripción literal, o acudiendo a su utilización encubierta o desdibujada para lo cual se modificaron algunas expresiones lingüísticas o giros idiomáticos.

\section{Extractos del decisorio:}

- "Di Marco, en dos obras suyas, vulneró los derechos intelectuales de la demandante, infringiendo la ley 11.723 de Propiedad Intelectual y la normativa complementaria, cometiendo un acto antijurídico al baber plagiado aquél trabajo en dos publicaciones de su autoría (arts. 1066, 1067 y concs. Cód. Civil; arts. 1708, 1716, 1717, 1721, 1724, 1725 y concs. CCCN). Los dos trabajos de María Cecilia Di Marco, en los que utilizó ilicitamente material intelectual de la actora, son los siguientes: 1) tesis de maestría "El Proceso de Desarrollo y Diversificación de la Universidad Argentina. El caso de la UNCPBA (1964-1975)"

- “...al contestar el traslado de la excepción de prescripción, Pastor reconoció -con efectos de admisión procesal- que tuvo noticia cierta y efectiva de la existencia de las mencionadas publicaciones dos meses antes del envío de la carta documento de Julio de 2014. En consecuencia, y en ausencia de prueba en contrario, resultando verosímil lo expuesto, por lo que la fecha de conocimiento efectivo fue "fines de Mayo de 2014". Adicionalmente no debe perderse de vista las circunstancias en que Pastor conoció la existencia de las publicaciones de Di Marco las que acaecieron en el marco de una actividad académica, en ocasión en que la Universidad Nacional del Centro organizó la publicación de un dossier de divulgación con motivo de celebrarse el Cincuenta Aniversario de su creación.

- “...aun cuando es cierto lo que afirma la demandada de que la ley 11.723 no define al plagio, la tipificación jurídica de dicho supuesto fáctico y jurídico ba sido efectuada desde antiguo por la doctrina y la jurisprudencia. En ese sentido la Corte Nacional sostuvo que "el art. 10 de la ley 11.723 ... importa una reglamentación razonable del derecho de autor, con miras a un fin de bien común" (CS, 31/10/1961, "Antonio Esteban Agüero 
v. S. A. Ángel Estrada y Cía.”, Fallos 251:155). Afirma Zavala Rodríguez que "la ley 11.723 no emplea tampoco en ninguno de sus artículos la palabra plagio u otra semejante, pero ba incorporado el concepto de este ataque a los derechos de autor y lo reprime. Es útil recordar-agrega-aquí el origen de la palabra plagio. En Roma la ley Fabia llamaba plagiario a la persona que hubiera robado el bijo de otro, o bubiera secuestrado, vendido o comprado una persona libre, o bubiese inducido a un esclavo a fugarse. El plagio -concluye el autor citado- es así entre nosotros un ataque al derecho moral. Si un autor mutila el título de una obra o cambia maliciosamente la forma para disfrazar la apropiación, el autor, sin perjuicio de las penas que fijan otras disposiciones de la ley, puede pedir que se restituya la obra a su forma primitiva (derecho moral) (arts. 36 y 51)" (cf. Zavala Rodríguez, Carlos Juan, "El plagio literario ante la Ley 11.723”, en J.A., $T^{\circ}$ 53, ps. 135 y sgtes.). En la sentencia que fue objeto del comentario citado de Zavala Rodríguez, el voto del juez Dr. Barraquero, señaló, en sentido concordante, que "la ley 11.723 no define el plagio-falsificación intelectual-, sino la falsificación o plagio material -impresión ilicita-, equiparada por los arts. 71 y 72 ley citada al delito de defraudación. La apreciación del plagio de una obra intelectual, de acuerdo a nuestro régimen legal-continuó-queda librada al juicio y a la sagacidad de los magistrados, quienes deben comparar las obras y pesar las semejanzas teniendo en cuenta la regla de que la copia es en principio deshonesta, y que está probibida cuando no es becha con el objeto de una discusión o polémica, sino para aprovechar el trabajo de otro y evitar la pena que originaría el esfuerzo de producir un trabajo original" (conf. Cám. Nac. Civil, 23/12/35, "Figueredo, Francisco v. Gonzaga, Antonio", J.A., T ${ }^{\circ}$ 53, pág. 136)”;

- Sobre esta base normativa, la doctrina destacó la importancia de ponderar como parámetro interpretativo que confiere legitimidad al uso de una obra ajena, "el denominado uso honrado" - fair use-, admitido por el Convenio de Berna ... que permite ciertas utilizaciones de una obra ajena sin solicitar 
autorización previa ni remunerar al autor, a condición de que se bagan conforme a los usos honrados y en la medida justificada por el fin que se persiga. Naturalmente, uno de esos parámetros sine qua non para este uso bonrado, o para el derecho de cita, es que las utilizaciones de las obras ajenas deberán mencionar en cada caso el trabajo y el nombre del autor" (Toller, Fernando M., "Propiedad intelectual y plagio en trabajos académicos y profesionales", pub. en Sup. Act. 26/10/2010, 26/10/2010, 1, Cita Online: AR/DOC/7206/2010).Todo ello en concordancia con lo prescripto por el art. 10 de la ley 11.723 (ver Millé, Antonio, "La información ante el derecho de la propiedad intelectual", págs. 93/94, en Derechos intelectuales, Ed. Astrea, 5). El autor citado, en otro trabajo, expresa que se puede acudir a las obras ajenas para trabajos propios cuando: a) debe tener una finalidad didáctica o científica; b) debe limitar la utilización hasta mil palabras en las obras literarias y ocho compases en las musicales; c) las partes del texto deben ser indispensables a ese efecto, $y$ d) la utilización debe ser en la forma de comentarios, críticas o notas... El derecho de cita nunca puede consistir en la apropiación de la obra ajena" (Emery, Miguel Á., en Código Civil y leyes complementarias. Comentado, anotado y concordado - Belluscio, Augusto C. -Director-Zannoni, Eduardo A. -Coordinador-, Tomo 8, págs. 335 y 337).

- Por todo lo expuesto, atento lo acordado al tratar las cuestiones anteriores, demás fundamentos del Acuerdo, citas legales, doctrina y jurisprudencia referenciada, y lo dispuesto por los arts. 266, 267 y concs. del C.P.C.C., se resuelve: 1) confirmar la sentencia de Primera Instancia en lo que ba sido objeto de recurso y agravio. 2) Imponer las costas de segunda instancia a cargo de la demandada vencida (art. 68 C.P.C.). 3) Diferir la regulación de honorarios para la oportunidad del art. 31 de la Ley 14.967. REGÍSTRESE. NOTIFÍQUESE por Secretaría y DEVUÉLVASE.

Tribunal: CAMARA DE APELACIONES EN LO CIVIL Y COMERCIAL. MORON, BUENOS AIRES 
Fallo: Industrias Metalúrgicas Nuperi e Hijos S.R.L. c/ Courtade Eduardo José y otro/a s/ daños y perj.resp.profesional

Voces: Locación de obra, responsabilidad civil, exclusión de la fuerza mayor.

\section{Sumario:}

- Comienza quejándose la parte actora de la consideración de la Sra. Juez de Grado en cuanto a la ajenidad, por parte de la demandada, de la construcción del techo parabólico.

- El constructor debe responder por el derrumbe del inmueble construido durante una catástrofe climática, debiendo indemnizar a la actora el daño material sufrido, toda vez que se encuentran suficientemente acreditados, mediante el dictamen pericial, los yerros constructivos que afectaban a la obra, de manera que un evento climático inusual incide sobre una obra con defectos constructivos y la destruye, en este contexto, el perito ha sido claro al señalar que ambos factores condujeron al colapso.

\section{Extractos del decisorios:}

- “...Insiste en que fue la conducta del demandado la que provocó la ruina total del inmueble de su parte y argumenta ampliamente en tal sentido, cuestionando el fallo en cuanto exoneró parcialmente al demandado, al considerar como concausal el evento meteorológico del 4 de Abril de 2012.- Sostiene, también, que no puede tomarse a este evento como caso fortuito o fuerza mayor, al existir culpa en el demandado, afirmando que el evento natural no posee nexo causal o concausal con la imprudencia y negligencia en la forma de construir por parte del demandado; y profundiza en tal sentido...";

- “...Habla del caso fortuito y evoca la conclusión pericial en el sentido de que con un viento de menor intensidad igual se bubiera desplomado de obra.";

- “...Por otro lado, la respuesta dada a fs. 1263vta. tercer párrafo (en el sentido de que no se puede afirmar de manera concluyente que si los anclajes hubieran sido correctos el 
edificio no se bubiera derrumbado) que pretende capitalizar la demandada en sus agravios, ello tampoco rebate una cuestión concluyente que es que, en realidad, los anclajes no eran correctos.- De este modo, lo que bipotéticamente pudiera haber sucedido (y no sucedió) es una cuestión meramente conjetural, que -desde mi punto de vista- no modifica la conclusión pericial que vengo refiriendo.- En suma: vienen suficientemente acreditados (mediante el dictamen pericial) los yerros constructivos que afectaban a la obra.- Eso es cierto.- Pero no menos cierto es que la obra en cuestión fue destruida por un evento climático que, si bien registraba algún antecedente, resultaba de suyo infrecuente.- No dejo de advertir, en este sentido, que el antecedente que refería el servicio meteorológico de vientos de esta intensidad tenía mas de una década (año 2001).- Entonces, un evento climático inusual incide sobre una obra con defectos constructivos y la destruye.- En este contexto, el perito ha sido claro al señalar que ambos factores condujeron al colapso...".

Tribunal: JUZGADO DE FAMILIA NRO 8. LA PLATA, BUENOS AIRES

Fallo: C. M. L. y otro/a s/ autorización judicial

Voces: Técnicas de Reproducción Humana Asistida, Código Civil y Comercial, Voluntad procreacional/consentimiento, Criopreservación, oficio al Poder Legislativo sobre la problemática.

\section{Sumario:}

- Corresponde hacer lugar al pedido de autorización efectuado por una pareja, para interrumpir la criopreservación de embriones generados por una técnica de reproducción humana asistida, hace más de diez años, y proceder a su descarte, debido a que los peticionantes no desean tener más hijos, dado que la decisión de la pareja forma parte de la esfera íntima y revela el proyecto de vida común que detentan en la actualidad, el cual debe ser respetado en los términos y alcances del artículo 19 de la $\mathrm{CN}$.

- Si bien los solicitantes en un principio han exteriorizado a través del consentimiento informado su voluntad procreacional 
resulta claro con la presentación que ya no desean agrandar la familia, desistiendo de aquella voluntad que los vinculó contractualmente con la Clínica en donde se encuentran los embriones.

\section{Extractos del decisorio:}

- "Manifiestan que con la primer transferencia embrionaria lograron el embarazo tan deseado habiendo nacido su hija A. L. A. C. Y que, en la actualidad, no es su deseo tener más bijos. Sin embargo, durante diez años han mantenido la criopreservación de dichos embriones, en un principio pensado que más adelante intentarían lograr un nuevo embarazo. Al día de la fecha han tomado la decisión de cesar la criopreservación y resolver el contrato que los une vitaliciamente con la Clinica P. No obstante, desde la misma les han manifestado que para interrumpir la criopreservación ante la falta de normativa expresa se requiere autorización judicial. Finalmente, señalan que carecen de voluntad procreacional, que no desean continuar atados a un contrato de tiempo indefinido y que tampoco tienen la voluntad de donarlos ni dejarlos para la investigación. 2.- Que en fecha 18 de julio de 2019 el Juzgado de Familia $n^{\circ} 6$ departamental se declaró incompetente para entender en el presente proceso en función de la atribución de competencia en los términos del art. $830 \mathrm{del} \mathrm{CPCC,} \mathrm{por} \mathrm{no} \mathrm{revestir} \mathrm{identidad}$ de partes conforme la ley indica..."

- "La herramienta que posibilitará arribar a una respuesta adecuada la encontramos en los arts. 1 y 2 del CCCN que dotan de elasticidad y flexibilidad al ordenamiento jurídico interno permitiendo el diálogo de fuentes con el afán de alcanzar soluciones que respeten el piso mínimo que emerge de la Constitución Nacional y los Tratados Internacionales de Derechos Humanos. Respecto a estos últimos, son incorporados al texto de la Constitución Nacional a partir de la reforma del año 1994 conformando el denominado "bloque de convencionalidad", receptándose en ese entonces de manera expresa el derecho a la vida. Entre ellos encontramos, la Declaración Americana de los Derechos y Deberes del Hombre que establece, "Todo ser humano 
tiene derecho a la vida..." (art. 1); la Declaración Universal de Derechos Humanos, "Todo individuo tiene derecho a la vida..." (art. 3); la Convención Americana sobre Derechos Humanos, "Toda persona tiene derecho a que se respete su vida..." (art. 4); el Pacto Internacional de Derechos Civiles y Politicos, "El derecho a la vida es inherente a la persona bumana...", impidiendo además la aplicación de la pena de muerte a las mujeres "en estado de gravidez" (art. 6 incs. $1^{\circ}$ y $5^{\circ}$ ); la Convención para la Prevención y Sanción del Delito de Genocidio que, entre otros actos, incluye la matanza de miembros de un grupo y la adopción de "medidas destinadas a impedir los nacimientos..." (art. 2 incs. $a y d$ ). Por último, la Convención sobre los Derechos del Niño establece, "Todo niño tiene derecho intrínseco a la vida" (Art. 6), definiendo al niño como todo ser bumano menor de dieciocho años de edad (Art. 1). Dicha Convención fue aprobada mediante la Ley $N^{\circ} 23.849$, que en el art. $2^{\circ}$ dispone "la República Argentina declara que (...) debe interpretarse en el sentido que se entiende por niño todo ser bumano desde el momento de su concepción y hasta los dieciocho años de edad". Del corpus iuris internacional dimana que el derecho a la vida es un derecho bumano inberente a toda persona, pero ¿cuándo comienza la existencia de la persona? (...) El Código Civil y Comercial de la Nación en el artículo 19, modificado con fecha 28 de noviembre de 2013 en la Cámara de Senadores, establece: "Comienzo de la existencia. La existencia de la persona bumana comienza con la concepción." Diferenciándose así del artículo proyectado originariamente donde se preveía, además, para el caso de técnicas de reproducción bumana asistida, que el comienzo de la existencia se produce con la implantación del embrión en la persona, sin perjuicio de lo que prevea la ley especial para la protección del embrión no implantado. El artículo responde a la tradición jurídica argentina. Los fundamentos del Anteproyecto expresaban que "no se varía el estatus legal del comienzo de la persona, en tanto se reconocen efectos desde la concepción en seno materno, como ocurre en el derecho vigente, a punto tal, que se ba conservado 
hasta su antigua terminología”. La quita sufrida en la Cámara de Senadores silencia una realidad que viven muchas parejas o personas solas que pretenden alcanzar la paternidad o maternidad a través del uso de las técnicas de reproducción bumana asistidas, obligando a la justicia a expedirse sobre situaciones, como la de autos, simplemente por la razón de no contar con una legislación clara y precisa que regule el tema.

- "De este modo, partiendo de la redacción actual del art. 19 del CCCN, si el derecho a la vida comienza a partir de la concepción, la cuestión -como ya be señalado-debe ser dilucidada a través de la interpretación jurídica y sistémica que se haga sobre este concepto en consonancia con los avances científicos que imperan en la materia. Circunstancia que ba dado lugar a grandes debates en doctrina ( $v$. Kemelmajer de Carlucci, Aída, Lamm, Eleonora, Herrera, Marisa, "Cuando voces autorizadas se suman para llegar a buen puerto: No a la actuación del asesor de menores como "Defensor de los Embriones"”, AR/DOC/3667/2014, LA LEY 14/10/2014 1 - LA LEY 2014-E, 1372; Villaverde, María Silvia, "La concepción", Revista de Derecho de Familia y de las Personas, (enero), La Ley, 2014, p. 147”.

- corresponde hacerlugar a la autorizaciónpretendidapor los interesados, correspondiendo -en función del consentimiento revocado- cesar el contrato que los une con la Clínica P. y, en consecuencia, cesar la criopreservación de los embriones que mantiene la pareja para su descarte. Sin embargo, a mayor abundamiento no puedo dejar de advertir que en el particular, los derechos de la pareja C. - A. se han visto vulnerados por parte del Estado, precisamente, por el poder legislativo al no receptar de manera clara, precisa y contundente la posición que ya ba fijado la Corte IDH; obligando a las personas que se encuentran en una situación similar a la de autos a judicializar una decisión que forma parte de la esfera intima y del proyecto de vida que cada uno considera mejor para sí. De la autonomía de voluntad receptada en la Constitución Nacional, se desprende la noción de autonomía "moral" y he aqui donde convergen 
las libertades individuales y las decisiones personales sobre la propia vida -lo que cada individuo sostiene como "moralmente correcto" para su vida-, decisiones que, en la medida que no afecten a terceras personas, la injerencia Estatal resulta inconstitucional (doc. art. 19 CN). La justicia no debe atender cuestiones que forman parte de la esfera intima de las personas, debido a ello, ponderando que urge brindar una respuesta legislativa sobre este tema, máxime cuando la mayoría de los diferentes proyectos presentados han perdido estado parlamentario (1326-S-2016, del 27/04/2016; 0007-D2016, 1/03/2016; 0091-D-2017, del 1/03/2017), subsistiendo actualmente el proyecto de ley número 1541-D-2019 que guarda coherencia con el ordenamiento jurídico y la visión constitucional-convencional que debe imperar, estimo que corresponde oficiar al poder legislativo nacional a los fines de poner en conocimiento -al menos- las dificultades que están obligados a atravesar los particulares ante la falta de legislación -en cumplimiento con la disposición transitoria $n^{\circ} 9$ de la ley 26.994-, como así también la labor jurisdiccional atípica, pues no existe controversia ni conflicto que resolver. POR ELLO, conforme lo normado por los arts. 34 incs. $3^{\circ} y$ $4^{\circ}, 163 \mathrm{del}$ CPCC; F A L L O: $1^{\circ}$ ) Hacer lugar a la autorización judicial solicitada, correspondiendo resolver el contrato que une a los peticionarios con la Clínica P. y, en consecuencia, cesar la criopreservación de los embriones que posee la pareja, procediendo a su descarte .- $2^{\circ}$ ) Oficiar por Secretaría a la Cámara de Diputados de la Nación y a la Cámara de Senadores de la Nación, a los fines de poner en conocimiento de las mismas acerca de las dificultades -al menos- que están obligados a atravesar los particulares, en situaciones similares, ante la falta de legislación vigente -en cumplimiento con la disposición transitoria contenida en el art. $9^{\circ}$ de la ley 26.994-, como así también la labor jurisdiccional atípica frente a la inexistencia de controversia .- $3^{\circ}$ ) Imponer las costas por su orden (art. $73 \mathrm{del}$ CPCC).- 
Tribunal : Juzgado Federal Civil, comercial, Constencioso Administrativo nro. 4 de La Plata

Fallo: "Perdomo Dinora C/ANseS S/Reajuste de haberes"

Voces: Derecho Previsional, Ley 27.426, Ley 26.417.

\section{Sumario:}

- Se declara la inconstitucionalidad de la ley 27426 y otorga la movilidad de la anterior ley 26417, para lo que fue el aumento de marzo de 2018 que fue de un 5,71\% cuando debería haber sido de $14,5 \%$ es decir aproximadamente un $9 \%$ menos, que arrastrado, es decir actualizado en el tiempo a la actualidad, determina una perdida mayor.

\section{Extractos del decisorio:}

- "la aplicación retroactiva antes aludida, atento el resultado precedentemente expuesto, vulnera los principios de progresividad y de no regresividad de los Derechos Económicos, sociales y culturales, consagrados en los Tratado Internacionales de Derechos Humanos, incorporados al texto de la Carta Magna, conforme el art. 75. Inc. 22 de la C.N. "La progresividad determina un sentido a la actuación estatal, e impone un deber formal, operativo e inmediato, cual es el de impedir la regresividad en el grado de tutela de los derechos consagrados. Así, el Estado argentino debe adoptar medidas necesarias hasta el máximo de sus recursos disponibles, sin discriminación, y tiene probibido conducir con su accionar o su desidia a una

4 El siguiente fallo se incluye en esta Sección por el impacto que tiene en la materia, ello sin perjuicio de que como se puede apreciar el Tribunal es Federal con asiento en La Plata. Asimismo, se agradece facilitar este material de Sección al Estudio Jurídico Presa - interviniente en la causa-, con las siguientes aclaraciones; El fallo no restablece la plena vigencia de la movilidad de la ley 26417, sino que solo para el mensual marzo de 2018, donde el aumento de los haberes previsionales, había sido calculado en el periodo junio a diciembre de 2017, fue confiscado por el apuro del gobierno al poner en vigencia la ley 27.426 el 28 de Diciembre con su publicación, pensando el que lo hizo en el ahorro de ese aumento que debió ser del $14,5 \%$ en solo un $5,71 \%$ Claro está que los reclamos son menores que los aumento.

Existen dos fallos más, importantes en la materia: "Arosteguy Francisco Guillermo c/ANseS s/Reajustes haberes" expte 130031/2018 y "Acha Norma Elida C/ANseS s/reajustes de Haberes" expte nro 112421/2018 
regresividad en el nivel o grado alcanzado con anterioridad en el goce de los derechos económicos, sociales y culturales. ...También cabe señalar lo decidido por el Alto Tribunal en autos "Arcuri Rojas, Elsa c/ ANSES", sentencia del 3 de noviembre de 2009, en donde sostuvo que "...es el reconocimiento del principio de progresividad en la satisfacción plena de esos derechos el que ha desterrado definitivamente interpretaciones que conduzcan a resultados regresivos en la materia (arts. 26 y 29 de la Convención Americana sobre Derechos Humanos y considerando $10^{\circ}$ del voto del Dr. Maqueda en Fallos: 328:1602)" (considerando 14)..." (del precedente de esta Sala "PAGANINI HECTOR RODOLFO C/ ANSES S/ REAJUTES VARIOS” EXPT. N": 24.015/2007 S. D. $N^{o}$ : 143555, del 15 de Febrero de 2012)”.

- "La modificación de la fórmula de cálculo de la movilidad, no puede proyectarse en perjuicio de los jubilados y pensionados, debiendo adoptarse la solución que mejor se adecue a los principios y garantías de la Constitución Nacional y favorezca la progresividad de los derechos bumanos".

- "Al respecto cabe recordar que el Alto Tribunal sostuvo que el artículo 75, inciso 23, de la Constitución Nacional fortalece la vigencia del principio de progresividad en materia previsional, descalificando todo accionar gubernamental que en la práctica de un resultado regresivo en el goce efectivo de los derechos (Fallos 331:250)".

- Declarar la inconstitucionalidad del art. 2 de la Ley 27.426, de conformidad con los considerandos precedentes, ordenando que la movilidad correspondiente al mes de marzo de 2018 sea determinada de conformidad con las pautas fijadas en la Ley 26.417, debiendo empezar a aplicarse la nueva movilidad establecida por Ley 27.426 a partir del incremento correspondiente al mensual septiembre 2018.

\section{SUPREMA CORTE DE JUSTICIA DE LA PROVINCIA DE BUENOS AIRES}

Fallo: P., A. F. c. Galeno ART S.A. s/ enfermedad profesional. 
Voces: Muerte por estrés laboral.

\section{Sumarios:}

- La familia de un trabajador fallecido promovió demanda alegando que su muerte se produjo debido al estrés laboral que sufría por jornada prolongada y la exposición por años a esta circunstancia, lo que había deteriorado su salud. Deducido el recurso de inaplicabilidad de ley, la Suprema Corte de Buenos Aires revocó la sentencia por absurda.

- El rechazo de la demanda por la muerte de un trabajador por estrés laboral fue absurdo, pues el juzgador concluyó que no se había probado el nexo de causalidad entre la muerte y las tareas desarrolladas por el dependiente como chofer de colectivo, cuando la pericia daba cuenta de la influencia concausal entre los factores personales de aquel -hipertensión arterial e hipercolesterolemia- y los factores externos —estrés, jornada prolongada y la exposición durante años-, determinando la influencia de estos últimos en un $60 \%$, frente al $40 \%$ por las predisposiciones personales.

\section{Extractos del decisorio:}

- "El tribunal de trabajo interviniente desestimó integramente la acción deducida por la señora A. F. P. —por sí y en representación de sus hijos menores de edad-, G. R. y A. A. -este último, boy mayor de edad-, J. I. y A. E. A. contra Galeno ART SA, en cuanto procuraban el cobro de una indemnización derivada del fallecimiento del señor R. A. A. -quien en vida fuera esposo y padre, respectivamente, de los accionantes...;

- tras valorar las pruebas rendidas en la causa, si bien tuvo por acreditado en el veredicto que este último trabajaba como chofer de colectivos para la empresa El Rápido de Lincoln SRL y el recorrido diario que realizaba en su labor, el órgano de grado consideró que no resultó probado en autos el estrés laboral padecido por el trabajador en el cual los actores basaron su demanda;

- Contra la sentencia de grado, se alza la parte actora mediante recurso extraordinario de inaplicabilidad de ley..." 
- el veredicto carece de fecha y de indicación del lugar en el que se dictó, incumpliendo de tal modo con las prescripciones contenidas en el primer párrafo del art. 47 de la ley 11.653. Asimismo, se observa que la secretaria del tribunal de origen no rubricó el mentado veredicto (...)

- “...cabe destacar que, en tanto los defectos apuntados constituyen falencias de forma (...) no conducen por sí solas a la anulación del pronunciamiento..."

- “...las características de las tareas desempeñadas por el trabajador, como así también la existencia de relación causal o concausal entre estas y el daño padecido, y en general el análisis de las cuestiones de becho y la apreciación del material probatorio, constituyen atribuciones privativas de los jueces de grado y ajenas a la casación, salvo que se demuestre el excepcional vicio de absurdo en la labor axiológica de los magistrados, que debe ser fehacientemente demostrado por quien lo invoca..."

- conforme surge de la reseña efectuada, el juzgador de grado evaluó la prueba producida —pericial médica y absolución de posiciones ficta-y determinó que los promotores del pleito no habian logrado demostrar el nexo de causalidad o concausalidad entre la muerte del señor A. y las tareas desarrolladas para su empleadora, ello, por cuanto no se babía acreditado el estrés denunciado - a la par-que sí se tuvieron por probadas las patologías inculpables padecidas por aquel.

- “...es preciso destacar que la experticia médica obrante a fs. 223/227 determinó que si bien la afección de salud por la cual falleció el actor era de carácter inculpable, "existe un factor a considerar que es la influencia del stress, situación a la cual todos nos vemos expuestos en mayor o menor medida, pero que debe considerarse de importancia en este caso, constituyendo un factor concausal en el desarrollo del cuadro si se prueba que el occiso desarrollaba tareas por jornadas laborales tan extensas como lo esgrimido por la actora";

- "Agregó el profesional médico que - en caso de que ello se probara-, conforme el Baremo de Altube Rinaldi, a los efectos 
de evaluar la influencia concausal entre los factores personales (bipertensión arterial e hipercolesterolemia) en relación con los factores externos (estrés, jornada prolongada y la exposición en años), se debía estimar a estos últimos en un $60 \%$ de influencia, frente al $40 \%$ por aquellas predisposiciones personales...";

- "...al momento de resolver la contienda, el tribunal de origen rechazó la demanda promovida, aun cuando tuvo por acreditadas las tareas de chofer de colectivo que realizaba el trabajador y -a través de las posiciones absueltas en rebeldía- el recorrido diario que efectuaba en su labor (v. vered., fs. 288 vta./289vta.). De alli que, su conclusión acerca de que la cantidad de horas de trabajo realizadas no resultaban prueba suficiente para demostrar el estrés como causante de la enfermedad profesional denunciada, se aparta arbitrariamente $y$ sin fundamento científico alguno del peritaje médico.”;

- “...no pudo el sentenciante - frente a las constancias de la causa-concluir que los accionantes no lograron acreditar con las pruebas rendidas en las actuaciones la relación de causalidad entre las tareas desarrolladas por el trabajador y su fallecimiento...";

- “...corresponde hacer lugar al recurso extraordinario de inaplicabilidad de ley traído y revocar la sentencia impugnada en cuanto incurrió en absurdo al considerar no demostrado el estrés como factor concausal de la enfermedad laboral denunciada..."

Fallo: Mourglia, Santiago Hipólito c. Dirección General de Cultura y Educación de la Pcia. de Bs. As. s/ Accidente de trabajo - Acción Especial.

Voces: Riesgos de Trabajo, Ley No 27. 348.

\section{Sumario:}

- Se trató de un juicio por accidente de trabajo declaró la inaplicabilidad al caso del procedimiento previsto en la ley 27.348 — de Riesgos del Trabajo- y decretó la inconstitucionalidad de los arts. 21, 22 y 46 de la ley 24.557 debe ser anulada 
de oficio, pues carece de la formalidad de acuerdo y voto individual, lo cual implica una transgresión a la cláusula del art. 168 de la Constitución de la Provincia de Buenos Aires.

\section{Extractos del decisorio:}

- "El Tribunal de Trabajo $N^{\circ} 1$ del Departamento Judicial de Lomas de Zamora, en el marco de un juicio por accidente de trabajo incoado por Santiago Hipólito Mourglia contra la Dirección General de Cultura y Educación de la Provincia de Buenos Aires, declaró — de oficio- la inaplicabilidad al caso del procedimiento previsto en la ley 27.348 y, haciendo lugar al planteo introducido por la parte actora, decretó la inconstitucionalidad de los arts. 21, 22 y 46 de la ley 24.557, con remisión expresa a lo resuelto por esta Suprema Corte de Justicia en el precedente "Quiroga, Juan Eduardo c. Ciccone Calcográfica SA s. Enfermedad"; sent. de 23/04/2003 (v.fs. 91/92)."

- "Frente a lo así resuelto, la Fiscalía de Estado dedujo recurso extraordinario de inaplicabilidad de ley[-] (v. fs. 94/98), el que fue concedido por esta Corte al resolver la queja incoada a fs. 124/127 (v. fs. 134/135 vta.)".

- "En este marco, visto que la decisión bajo censura resuelve en la presente litis una cuestión esencial, se advierte que carece de la formalidad de acuerdo y voto individual, lo que, en el caso, constituye transgresión a la cláusula del art. 168 de la Constitución provincial, cuyo cumplimiento resulta ineludible, correspondiendo su anulación oficiosa por esta Corte (causas L. 112.717, "Lasala", resol. de 30/03/2011; L. 117.364, "Coliqueo", resol. de 12/06/2013 y L. 120.805, "Gatica Estropio", resol. 13/09/2017). Por ello, la Suprema Corte de Justicia resuelve: Anular de oficio el pronunciamiento impugnado, remitiéndose los autos al tribunal de origen, para que, debidamente integrado, dicte nuevo pronunciamiento (art. 168, Const. prov.). Regístrese, notifíquese y devuélvase. - Luis E. Genoud. - Hilda Kogan. - Eduardo J. Pettigiani. — Sergio G. Torres." 